\title{
Gastric intramural hematoma: A case report and literature review
}

\author{
Vivek Dhawan MD PhD ${ }^{1}$, Ahmed Mohamed MD², Richard N Fedorak MD²
}

\begin{abstract}
V Dhawan, A Mohammed, RN Fedorak. Gastric intramural hematoma: A case report and literature review. Can J Gastroenterol 2009;23(1):19-22
\end{abstract}

Intramural hematoma of the gastrointestinal tract is an uncommon occurrence, with the majority being localized to the esophagus or duodenum. Hematoma of the gastric wall is very rare, and has been described most commonly in association with coagulopathy, peptic ulcer disease, trauma, and amyloid-associated microaneurysms. A case of massive gastric intramural hematoma, secondary to anticoagulation therapy, and a gastric ulcer that was successfully managed with conservative therapy, is presented. A literature review of previously reported cases of gastric hematoma is also provided.

Key Words: Anticoagulation; Gastrointestinal bleeding; Gastric intramural hematoma; Gastric ulcer; Hematoma; Peptic ulcer disease

Tntramural hematoma of the gastrointestinal tract is an 1 uncommon disorder (1). Most of these hematomas are localized either in the esophagus or in the duodenum. They can be idiopathic in nature (2) or they can result from endoscopic therapy $(3,4)$, coagulopathy $(5,6)$, peptic ulcer disease, trauma (7) or repeated vomiting (8). Hematoma of the stomach wall is rare, and only a few case reports describe this condition (8). A case of a gastric hematoma successfully managed with conservative therapy is presented.

\section{CASE PRESENTATION AND DIFFERENTIAL DIAGNOSIS}

A 69-year-old man was admitted to a community hospital where he was treated for five days for acute exacerbation of chronic obstructive pulmonary disease and pneumonia. While in the hospital, the patient developed hematemesis, and his hemoglobin dropped to $44 \mathrm{~g} / \mathrm{L}$. Due to absence of emergent transfusion capacity and an endoscopic facility, the patient was transferred to the University of Alberta Hospital, Edmonton, Alberta. While at the community hospital, the patient provided a history of intermittent black stools for the past three weeks. There was no history of abdominal pain, previous gastrointestinal bleeding, changes in bowel habit or constitutive symptoms. There was no history of liver disease. Medical history was significant for abdominal aortic aneurysm repaired by endovascular graft one year previously (the exact site of the

\section{Un hématome intramural gastrique : Un rapport de cas et une analyse bibliographique}

\begin{abstract}
L'hématome intramural du tube digestif est peu courant, la majorité des cas se situant dans l'œesophage ou le duodénum. L'hématome de la paroi gastrique est très rare et a surtout été décrit en association avec une coagulopathie, un ulcère gastroduodénal, un traumatisme ou un microanévrisme associé à des substances amyloïdes. Est présenté un cas d'hématome intramural gastrique massif, secondaire à la prise d'anticoagulants et à un ulcère gastroduodénal bien pris en charge par un traitement classique. Une analyse bibliographique des cas d'hématomes intramuraux gastriques déjà déclarés est également présentée.
\end{abstract}

${ }^{1}$ Department of Internal Medicine; ${ }^{2}$ Division of Gastroenterology, University of Alberta, Edmonton, Alberta

Correspondence: Dr Richard N Fedorak, Division of Gastroenterology, University of Alberta, 130 University Campus, Zeidler Ledcor Building,

Edmonton, Alberta T6G 2X8. Telephone 780-492-6941, fax 780-492-8121, e-mail richard.fedorak@ualberta.ca

Received for publication July 24, 2008. Accepted August 18, 2008

graft was not known at this point), peripheral vascular disease, previous stroke, hypertension, dyslipidemia, alcohol abuse, chronic renal failure with a baseline serum creatinine of $250 \mu \mathrm{mol} / \mathrm{L}$, chronic obstructive pulmonary disease, gout, cellulitis of the left foot and gastroesophageal reflux. Current medications included warfarin, clopidogrel, acetylsalicylic acid, lisinopril, amlodipine, lansoprazole, imovane, lorazepam, albuterol, atorvastatin, multivitamin and ferrous gluconate.

On arrival, the patient was hemodynamically unstable, requiring intubation, intravenous fluids and packed red blood cells. Cardiovascular examination was within normal limits except for bilateral crackles at both lung bases. Abdominal examination was unremarkable. There were no signs of peritonitis or chronic liver disease. A digital rectal examination revealed occult blood-positive feces.

Laboratory investigations were remarkable except for a white blood cell count of $12.3 \times 10^{9} / \mathrm{L}$, neutrophils $10.8 \times 10^{9} / \mathrm{L}$, platelet count $185 \times 10^{9} / \mathrm{L}$, partial thromboplastin time of $31 \mathrm{~s}$, international normalized ratio of 2.5 , creatinine $263 \mu \mathrm{mol} / \mathrm{L}$ and urea $33.7 \mathrm{mmol} / \mathrm{L}$.

Five units of packed red blood cells raised the patient's hemoglobin from $44 \mathrm{~g} / \mathrm{L}$ to $76 \mathrm{~g} / \mathrm{L}$. Two units of fresh frozen plasma, $10 \mathrm{mg}$ of vitamin $\mathrm{K}$ and desmopressin were provided to reverse coagulopathy. Intravenous pantoprazole and octreotide were initiated for a presumed upper gastrointestinal bleed of unknown origin. After initial resuscitation, the patient was admitted to the intensive care unit for further management. 


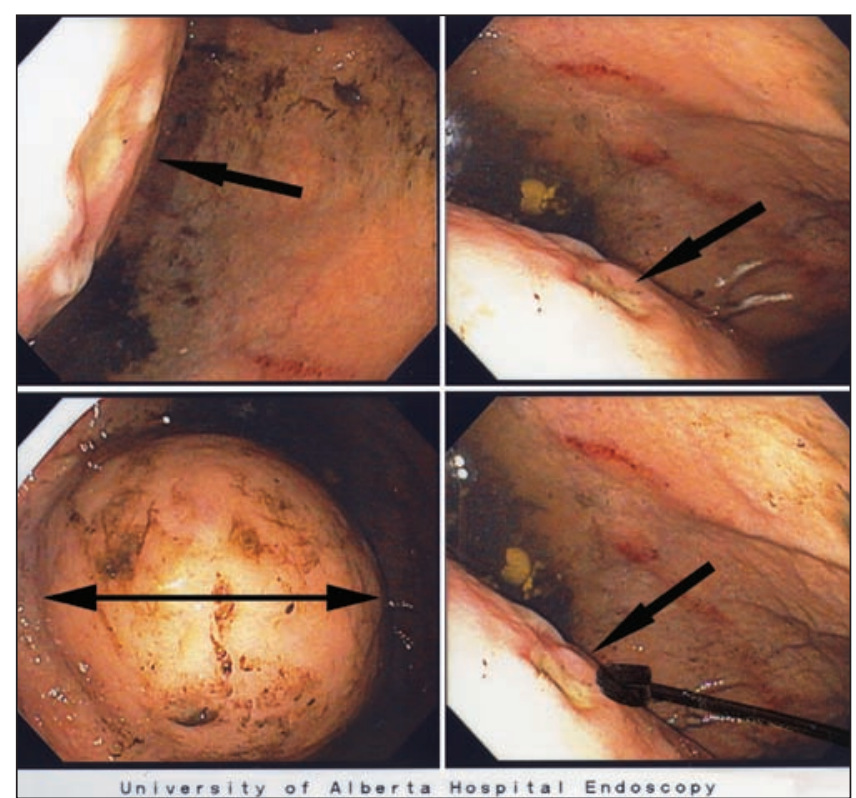

Figure 1) Gastric endoscopy showing a large intramural mass (double-headed black arrow) on the posterior-inferior wall of the stomach near the fundus. The three single-headed black arrows identify different views of the $5 \mathrm{~mm}$ shallow ulcer overlying the top of the intramural mass

Once the patient was hemodynamically stable, an upper endoscopy was performed. No evidence of esophageal or gastric varices was found. In the mid-body of the stomach, a large $8 \mathrm{~cm}$ extrinsic mass over the posterior-inferior surface of the stomach was identified (Figure 1). Over the surface of the mass was a $5 \mathrm{~mm}$ ulcer with a flat nonbleeding red spot at its base (Figure 1). Given the patient's history of aortic aneurysm repair with an endovascular graft (site unknown), the extrinsic mass was considered to be associated with a graft aneurysm and the ulcer, an aortoenteric fistula, as the bleeding site. The remainder of the stomach was endoscopically normal. The duodenum was normal except for a nonbleeding $2 \mathrm{~mm}$ superficial erosion with a white base in the second part. No hemostatic injections or biopsies of the extrinsic mass or ulcer were performed to avoid complicating a possible aortic graft aneurysm and aortoenteric fistula.

On completion of the upper endoscopy, the working diagnosis was an aortogastric fistula in the presence of an aortic graft aneurysm. The differential diagnoses included an intramural gastric neoplasia, likely a gastric leiomyoma or gastric hematoma. To further investigate this mass, a computed tomography (CT) angiogram was performed

A CT angiogram demonstrated an aortobifemoral graft complicated by a proximal pseudoaneurysm, which had been repaired with an endovascular stent (Figure 2). This appearance had not changed when compared with a CT performed six months earlier. Specifically, there was no extravasation of contrast and no proximal extension of the aneurysm into the gastric region of the abdomen, confirming that the decrease in hemoglobin level was not secondary to an aortogastric fistula. No hepatic, splenic or pancreatic abnormalities were identified. However, there was a large, fluid-filled cystic mass coursing along the posterior aspect of the stomach, from the level of the fundus to the mid-body. The mass was homogeneous, intramural and measured $8 \mathrm{~cm} \times 16 \mathrm{~cm}$. At the caudal aspect of the cystic mass was a discrete, hypodense area consistent with active
TABLE 1

Published literature on gastric intramural hematoma

\begin{tabular}{|c|c|c|c|c|}
\hline \multirow[b]{2}{*}{ Cause } & \multirow[b]{2}{*}{ References } & \multirow[b]{2}{*}{$\begin{array}{c}\text { Cases, } \\
\text { n (\%) }\end{array}$} & \multicolumn{2}{|c|}{ Management } \\
\hline & & & Conservative & $\begin{array}{c}\text { Surgical } \\
\text { intervention }\end{array}$ \\
\hline \multicolumn{5}{|l|}{ Coagulopathy } \\
\hline Hemophilia & $5,6,14,17-19$ & $6(23.1)$ & 6 & 0 \\
\hline Anticoagulation & $8,9,20,21$ & $4(15.4)$ & 3 & 1 \\
\hline Others & $16,22-24$ & $4(15.4)$ & 0 & 4 \\
\hline Aneurysm & $25-28$ & $4(15.4)$ & 1 & 3 \\
\hline Peptic ulcer disease & $12,13,29$ & $3(11.5)$ & 0 & 3 \\
\hline Spontaneous & $2,24,30$ & $3(11.5)$ & 1 & 2 \\
\hline Other causes & 7,27 & $2(7.6)$ & 2 & - \\
\hline Total & & 26 & 13 & 13 \\
\hline
\end{tabular}

arterial contrast extravasation. This fluid-filled cystic mass was not communicating with the aorta and was a significant distance from the endovascular graft site (Figure 2B).

These findings confirmed the diagnosis of an intramural gastric hematoma with a central bleeding ulceration, and correlated with the endoscopic appearance. It was hypothesized that the patient's warfarin-associated anticoagulation therapy accelerated bleeding from a shallow benign gastric ulcer, with the arterial vessel bleeding into the intramural tissue plane as well as intraluminal. The patient was managed conservatively with reversal of the coagulopathy, and fluid and blood replacement. There was no further ulcer bleeding and the intramural gastric hematoma resolved on follow-up over the next eight weeks.

\section{DISCUSSION}

Although intramural hematomas of the gastrointestinal tract have been described, intramural gastric hematoma is extremely rare. A PubMed search for all reported adult cases of intramural gastric hematoma in the English literature was performed and identified 26 cases (Table 1 ).

\section{Diagnosis of gastric hematomas}

In earlier case reports (5,9-13), upper gastrointestinal barium studies were used to investigate gastric hematomas. However, barium studies cannot readily distinguish a gastric hematoma from a solid tumour mass. Similarly, ultrasound has poor discriminatory capacity for gastric hematomas, showing an anechoic or hypoechoic pattern that is nonspecific and can mimic gastrointestinal neoplasm or inflammatory lesions $(13,14)$.

The CT scan is the current diagnostic procedure of choice for gastrointestinal-wall hematomas because it has the ability to precisely differentiate whether a mass is solid or liquid. In 1982, Plojoux et al (15) reported the use of CT scanning to diagnose intramural hematoma of the small bowel. They described gastrointestinal hematomas as well-circumscribed, high-density homogeneous masses. Unlike gastrointestinal neoplasms, gastrointestinal hematomas lack signs of calcification and infiltration into other organs.

Angiography has also been used to diagnose gastric hematomas, although the primary reason for using this modality was therapeutic rather than diagnostic $(8,16)$.

\section{Management of gastric hematomas}

Gastric hematomas secondary to intrinsic coagulopathy are generally managed conservatively. All six reported cases 

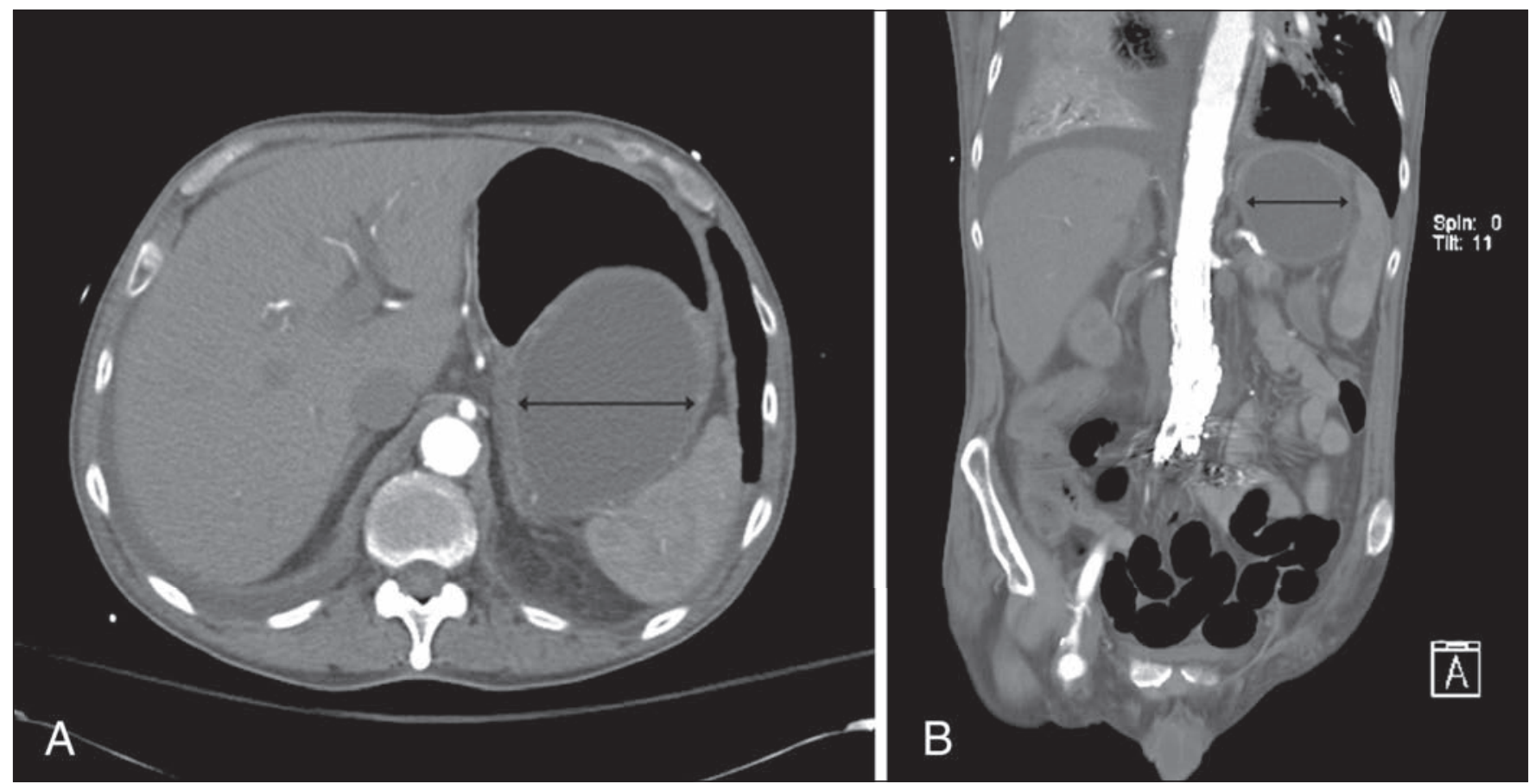

Figure 2) Cross-sectional (A) and longitudinal (B) computed tomography scan with intravenous contrast images of the abdomen showing a well-defined homogeneous mass involving the inferior-posterior portion of the stomach (double-headed black arrow). Note that the mass is not communicating directly with the aorta and that it is significantly superior to the site of endovascular graft

$(5,6,14,17-19)$ of gastric hematomas secondary to hemophilia were managed through blood and coagulation factor replacement. Nevertheless, bleeding can be massive because one of the six documented patients died from ongoing hemorrhage (6).

There are only four reported cases of gastric hematomas associated with anticoagulation therapy $(8,9,20,21)$. Only one of the four cases required therapeutic transcatheter arterial embolization (8). In that case, angiography revealed active extravasation of the contrast medium from the gastroparietal branch of the left gastric artery. The remaining three cases were managed conservatively with blood transfusions and reversal of the anticoagulation.

A surgical approach has also been used in the management of gastric hematomas. However, in both of the reported cases, amyloidosis with vascular microaneurysms, and persistent and repetitive bleeding was identified $(22,23)$. One of the two patients died after surgery as a result of multiorgan failure secondary to hypovolemic shock (22) while the second patient had a favourable postoperative course (23).

\section{REFERENCES}

1. Hughes CE III, Conn J Jr, Sherman JO. Intramural hematoma of the gastrointestinal tract. Am J Surg 1977;133:276-9.

2. Hui J, AhChong AK, Mak KL, Chiu KM, Yip AW. Spontaneous intramural hematoma of stomach. Dig Surg 2000;17:524-7.

3. Sollfrank M, Koch W, Waldner H, Rudisser K. Intramural duodenal hematoma after endoscopic biopsy. Rofo 2001;173:157-9.

4. Sugai K, Kajiwara E, Mochizuki Y, et al. Intramural duodenal hematoma after endoscopic therapy for a bleeding duodenal ulcer in a patient with liver cirrhosis. Intern Med 2005;44:954-7.

5. Griffin PH, Chopra S. Spontaneous intramural gastric hematoma: A unique presentation for hemophilia. Am J Gastroenterol 1985;80:430-3.

6. Melato M, Falconieri G, Manconi R, Bucconi S. Intramural gastric hematoma and hemoperitoneum occurring in a patient affected by idiopathic myelofibrosis. Hum Pathol 1980;11:301-2.
The patient reported in the present case study was therapeutically anticoagulated with warfarin. Similar to previous reports, the diagnosis was confirmed with a CT scan and the patient was treated with conservative therapy. The patient recovered fully with no reccurrence during eight months of follow-up. Nevertheless, the patient experienced additional renal insufficiency secondary to hypovolemia, and CT contrast agent-induced nephropathy and required transient hemodialysis.

In this patient, it is likely that the small gastric ulcer was the initiating site for the gastric hematoma, with bleeding from the arterial vessel separating intramural gastric planes leading to intramural bleeding and the hematoma.

\section{CONCLUSION}

Gastric hematoma is a rare disorder. CT of the abdomen is the diagnostic modality of choice. Gastric hematomas secondary to coagulopathy can usually be managed with a conservative approach, and surgery should be reserved for hematomas secondary to structural abnormalities of either the gastric wall or gastric blood vessels.

7. Crema MD, Monnier-Cholley L, Maury E, Tubiana JM, Arrive L. What is your diagnosis? Extra-pleural hematoma. J Radiol 2004;85(4 Pt 1):419-21.

8. Imaizumi H, Mitsuhashi T, Hirata M, et al. A giant intramural gastric hematoma successfully treated by transcatheter arterial embolization. Intern Med 2000;39:231-4.

9. Balthazar EJ, Einhorn R. Intramural gastrointestinal hemorrhage. Clinical and radiographic manifestations. Gastrointest Radiol 1976;3:229-39.

10. Elliott S, Bruce J. Submucosal gastric haematoma: A case report and review of the literature. Br J Radiol 1987;60:1132-5.

11. Lloyd TV, Johnson JC. Intramural gastric hematoma secondary to splenic rupture. South Med J 1980;73:1675-6.

12. Rothstein JD, Sandusky WR, Keats TE. Hematoma as a cause of radiographic deformity of stomach. Radiology 1968;90:116-7. 
13. Sheward SE, Davis M, Amparo EG, Gogel HK. Intramural hemorrhage simulating gastric neoplasm. Gastrointest Radiol $1988 ; 13: 102-4$.

14. Morimoto K, Hashimoto T, Choi S, et al. Ultrasonographic evaluation of intramural gastric and duodenal hematoma in hemophiliacs. J Clin Ultrasound 1988;16:108-13.

15. Plojoux O, Hauser H, Wettstein P. Computed tomography of intramural hematoma of the small intestine: A report of 3 cases. Radiology 1982;144:24.

16. Kami M, Matsukura A, Kanda Y, Ogawa S, Makuuchi M, Hirai H. Intramural hematoma of stomach after splenectomy for idiopathic thrombocytopenic purpura. Haematologica 1999;84:669-71.

17. Felson B. Intramural gastric lesion with sudden abdominal pain. JAMA 1974;230:603-4.

18. Griffin PH, Schnure FW, Chopra S, Brooks DC, Gilliam JI. Intramural gastrointestinal hemorrhage. J Clin Gastroenterol 1986;8(3 Pt 2):389-94.

19. Wright FW, Matthews JM. Hemophilic pseudotumor of the stomach. Radiology 1971;98:547-9.

20. Durward QJ, Cohen MM, Naiman SC. Intramural hematoma of the gastric cardia. Am J Gastroenterol 1979;71:301-5.

21. Leborgne L, Mathiron A, Jarry G. Spontaneous intramural gastric haematoma as a complication of oral anticoagulant therapy mimicking acute myocardial infarction. Eur Heart J 2007;28:1804.

22. Iijima-Dohi N, Shinji A, Shimizu T, et al. Recurrent gastric hemorrhaging with large submucosal hematomas in a patient with primary AL systemic amyloidosis: Endoscopic and histopathological findings. Intern Med 2004:43:468-72.

23. Muraki M, Kanno Y, Higuchi K, et al. Laceration of gastric mucosa associated with dialysis-related amyloidosis. Clin Nephrol 2005;64:448-51.

24. Costa BP, Manso C, Baldaia C, Alves FC, Sousa FC. Gastric pseudotumor. Hepatogastroenterology 2000;47:151-4.

25. Langlois NE, Miller ID. Intramural gastric hematoma originating from an atherosclerotic aneurysm of a gastric artery. Am J Gastroenterol 1993;88:613-4.

26. Matsuo S, Yamaguchi S, Miyamoto S, et al. Ruptured aneurysm of the visceral artery: Report of two cases. Surg Today 2001;31:660-4.

27. Molnar P, Miko T. Multiple arterial caliber persistence resulting in hematomas and fatal rupture of the gastric wall. Am J Surg Pathol 1982;6:83-6.

28. Nishiyama S, Zhu BL, Quan L, Tsuda K, Kamikodai Y, Maeda H. Unexpected sudden death due to a spontaneous rupture of a gastric dissecting aneurysm: An autopsy case suggesting the importance of the double-rupture phenomenon. J Clin Forensic Med 2004;11:268-70.

29. Ng SC, Shariff M, Datta D, Hanna G, Holdstock G. Gastrointestinal: Gastric wall hematoma. J Gastroenterol Hepatol 2006;2:915.

30. Rajagopal KV, Alvares JF. Spontaneous giant intramural hematoma of esophagus and stomach. Indian J Gastroenterol 2005;24:88. 


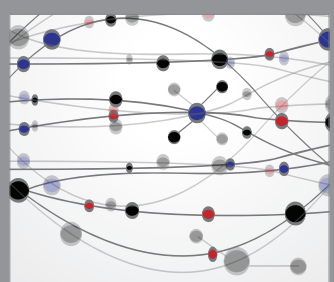

The Scientific World Journal
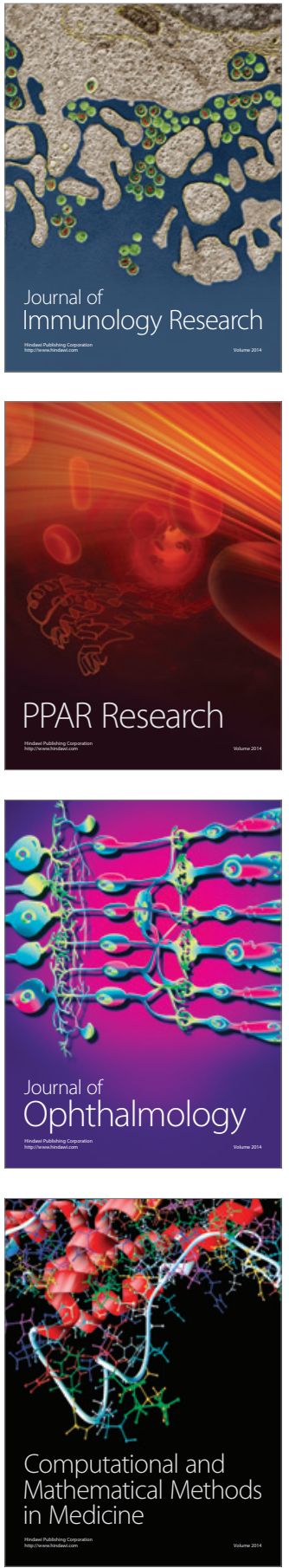

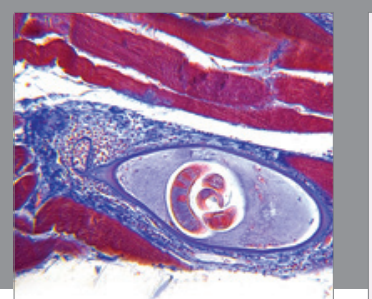

Gastroenterology Research and Practice

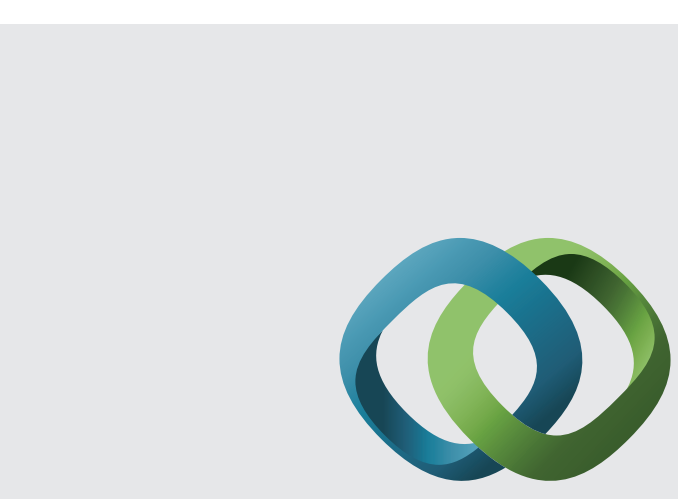

\section{Hindawi}

Submit your manuscripts at

http://www.hindawi.com
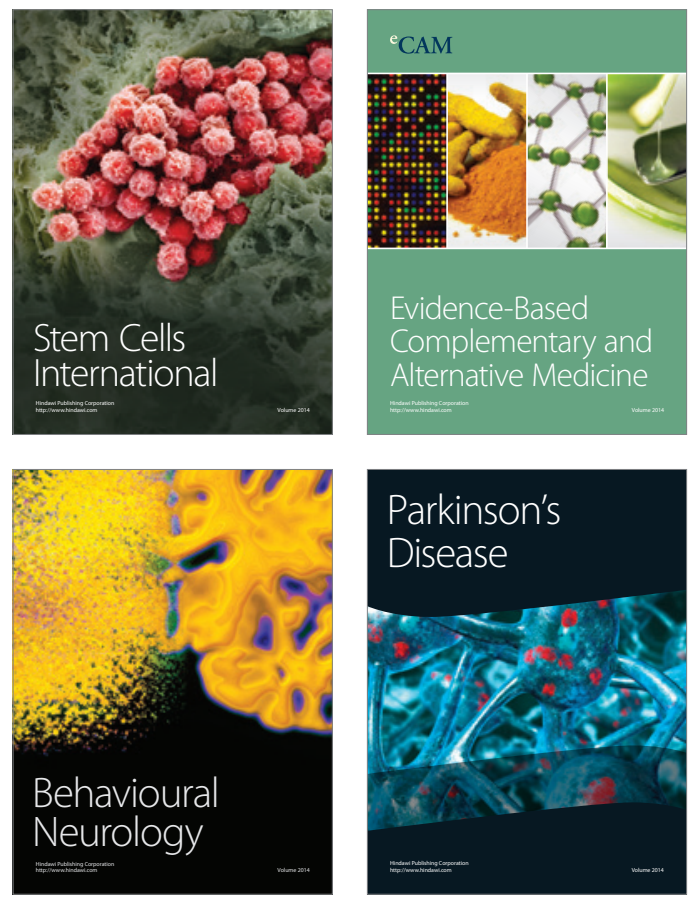
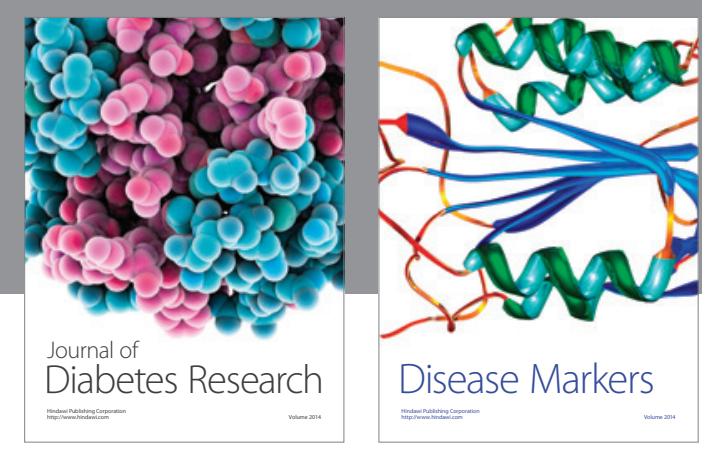

Disease Markers
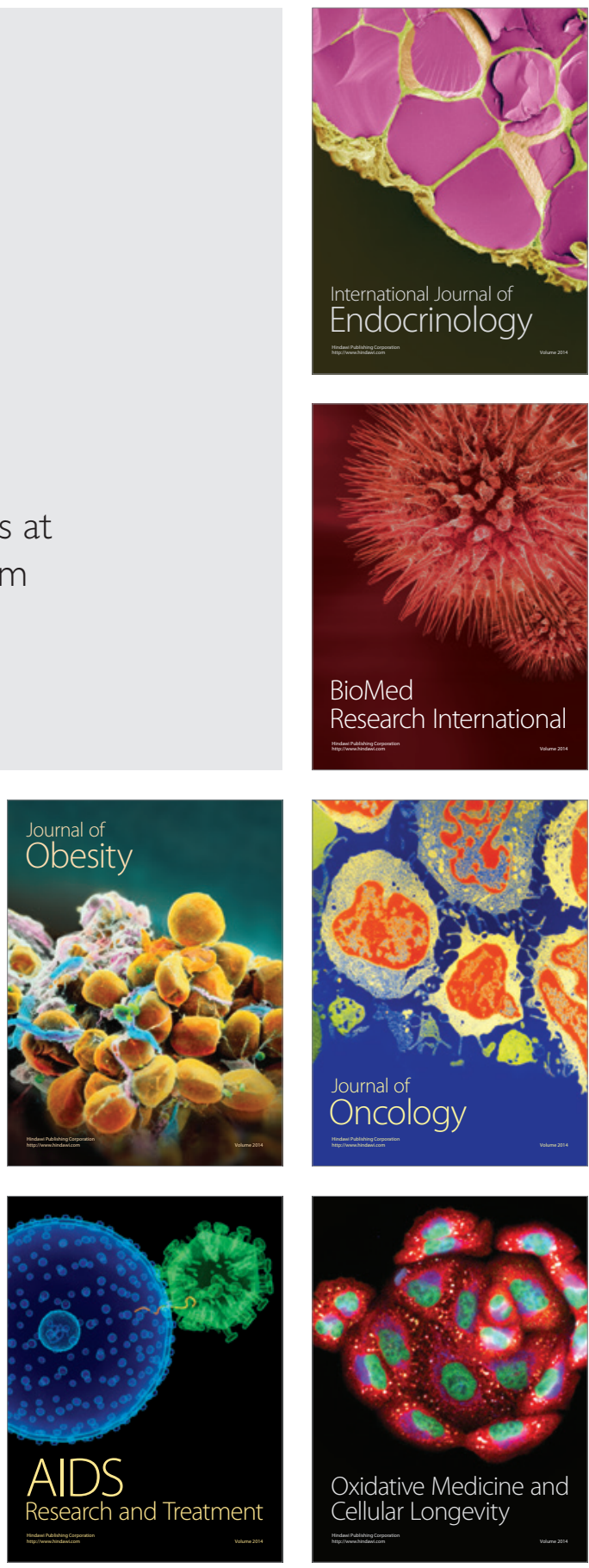